\title{
Thank you Dr Alan Thompson and Dr Noel Williams!
}

\section{"The destination of all journeys is their beginning." Angela Olive Carter}

$\mathrm{W}$ hen we set out on a journey to a place we've never been, on a road we've never travelled, we never know exactly how difficult the journey will be or where we will end up. Drs Thompson and Williams set out on such a journey in the autumn of 1987 when they agreed to take on the role of Co-Editors-in-Chief of a new journal called The Canadian Journal of Gastroenterology.

They never knew where this journey would take them, the perils that lay ahead or the obstacles that they would face, yet they embraced the challenge with enthusiasm and vision.

It was not easy, but it was a journey that grew to be successful beyond anyone's expectations.

There were times when there was a shortage of papers and the Journal survived only with the help of the Co-Editors, who stepped in and sent in all their work, including studies that could have been published in what were considered to be more prestigious journals at that time. Without Drs Thomson and Williams, the Journal would simply not exist today.

For some 13 years, Drs Thomson and Williams worked re- lentlessly to make The Canadian Journal of Gastroenterology one of the most successful Canadian medical publications, one that is widely distributed, read and admired, not only in Canada, but also worldwide. It is indexed by most major medical indexing services, including the Current Contents and Index Medicus - an achievement to be proud of indeed.

Canadian gastroenterologists and, for that matter, the medical community in Canada and abroad, benefit today and will for generations to come from the journey that Drs Thomson and Williams took into the unknown 13 years ago.

To express our appreciation for their hard work and dedication, Pulsus Group Inc is initiating and sponsoring a new award in honour of Drs Thomson and Williams. Further details will be announced at the Canadian Digestive Diseases Week in Quebec City.

Thank you for everything Alan and Noel.

Robert B Kalina

Publisher 


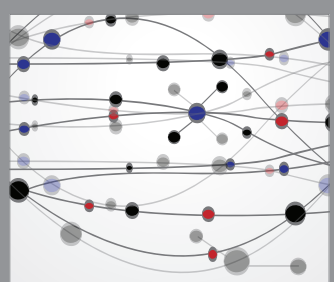

The Scientific World Journal
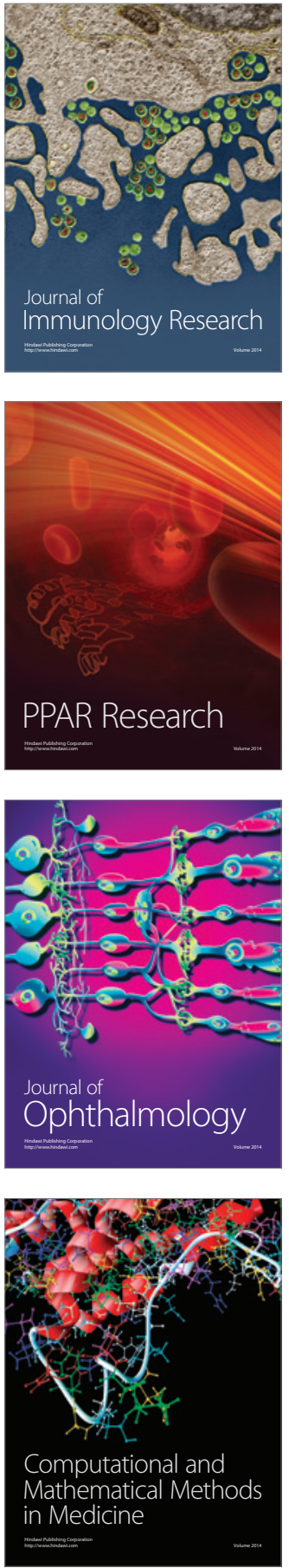

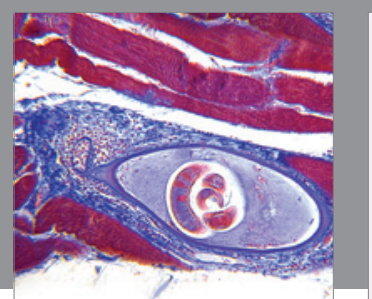

Gastroenterology Research and Practice

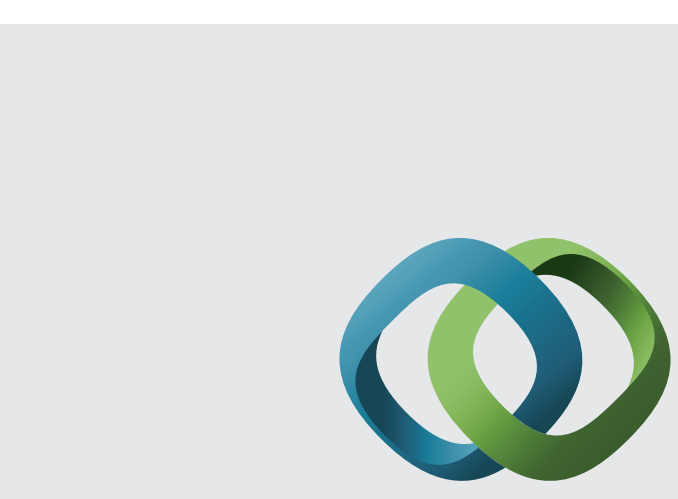

\section{Hindawi}

Submit your manuscripts at

http://www.hindawi.com
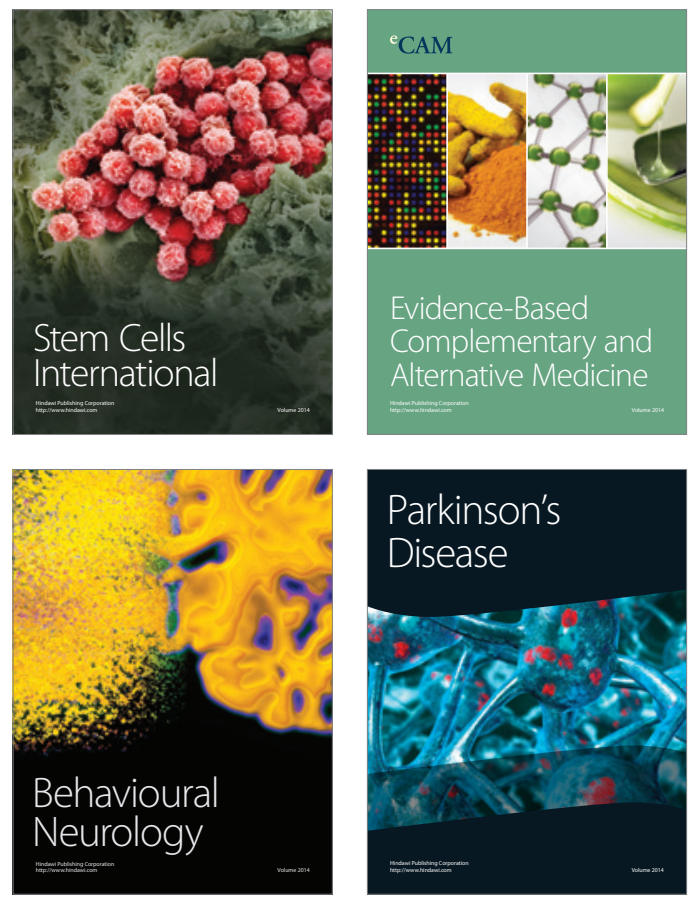
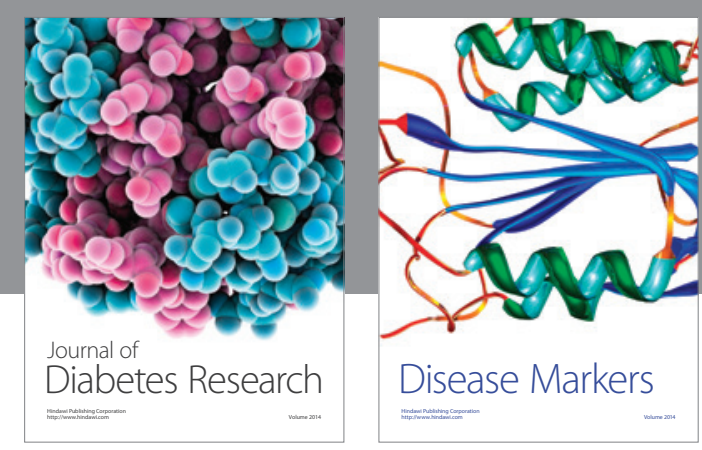

Disease Markers
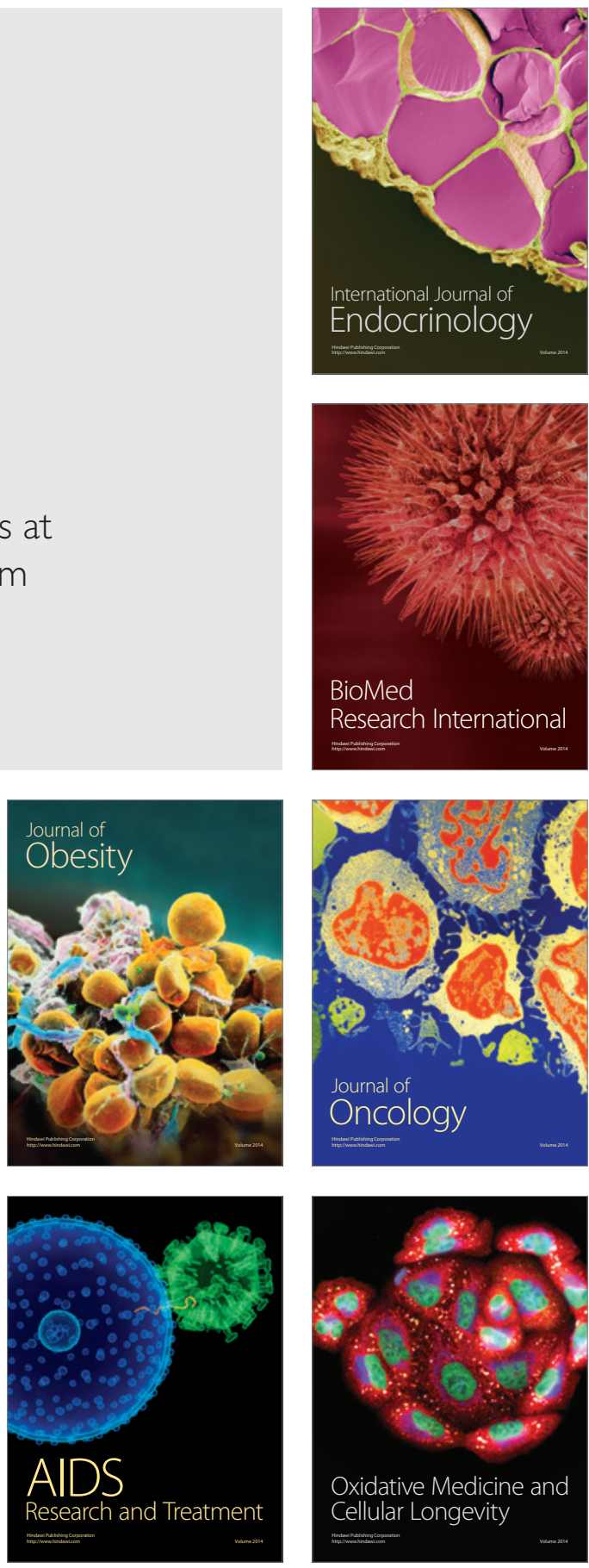